\title{
HIV vulnerability among adolescent girls and young women: a multi- country latent class analysis approach
}

\author{
Sanyukta Mathur ${ }^{1} \cdot$ Nanlesta Pilgrim $^{2} \cdot$ Sangram Kishor Patel $^{3} \cdot$ Jerry Okal ${ }^{4}$ - Victor Mwapasa ${ }^{5}$. \\ Effie Chipeta $^{5} \cdot$ Maurice Musheke $^{6} \cdot$ Bidhubhusan Mahapatra $^{3} \cdot$ Julie Pulerwitz $^{1}$
}

Received: 3 June 2019/Revised: 6 February 2020 / Accepted: 11 March 2020/Published online: 9 April 2020

(C) The Author(s) 2020

\begin{abstract}
Objectives To stem the HIV epidemic among adolescent girls and young women (AGYW, 15-24 years), prevention programs need to reach AGYW who are most at risk. We examine whether individual- and household-level factors could be used to define HIV vulnerability for AGYW.

Methods We surveyed out-of-school AGYW in urban and peri-urban Kenya $(N=1014)$, in urban Zambia $(N=846)$, and in rural Malawi $(N=1654)$ from October 2016 to 2017. LCA identified classes based on respondent characteristics, attitudes and knowledge, and household characteristics. Multilevel regressions examined associations between class membership and HIV-related health outcomes.

Results We identified two latent classes—-high and low HIV vulnerability profiles—among AGYW in each country; $32 \%$ of the sample in Kenya, 53\% in Malawi, and 51\% in Zambia belonged to the high vulnerability group. As compared to AGYW with a low-vulnerability profile, AGYW with a high-vulnerability profile had significantly higher odds of HIVrelated outcomes (e.g., very early sexual debut, transactional sex, sexual violence from partners).

Conclusions Out-of-school AGYW had differential vulnerability to HIV. Interventions should focus on reaching AGYW in the high HIV vulnerability profiles.
\end{abstract}

Keywords Transactional sex $\cdot$ IPV $\cdot$ Gender equity $\cdot$ STI $\cdot$ Condom use

\section{Introduction}

Sanyukta Mathur and Nanlesta Pilgrim contributed equally to the work.

This article is part of the special issue "Sexual and reproductive health of young people - Focus Africa". The Rudolf Geigy Foundation (Basel, Switzerland) funded the open access publication of this article.

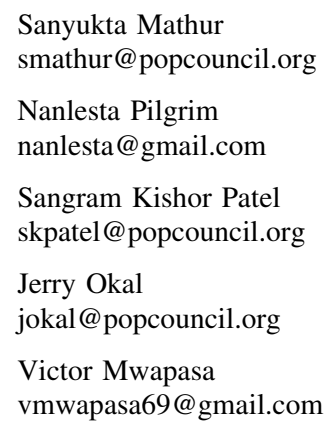

Sanyukta Mathur

smathur@popcouncil.org

Nanlesta Pilgrim

nanlesta@gmail.com

Sangram Kishor Patel

skpatel@popcouncil.org

Jerry Okal

jokal@popcouncil.org

Victor Mwapasa

vmwapasa69@gmail.com

Nearly four decades into the HIV epidemic, HIV rates among adolescent girls and young women (AGYW, females aged 15-24 years) remain intractable in many settings. Over 1000 AGYW become infected with HIV daily (UNAIDS 2016b). In eastern and southern Africa, AGYW are at considerably higher risk of HIV acquisition

\author{
Effie Chipeta \\ echipeta@medcol.mw \\ Maurice Musheke \\ mushekem@yahoo.com \\ Bidhubhusan Mahapatra \\ bbmahapatra@popcouncil.org \\ Julie Pulerwitz \\ jpulerwitz@popcouncil.org \\ Extended author information available on the last page of the article
}


compared to their male counterparts. According to estimates, of the nearly 290,000 new HIV infections in eastern and southern Africa among 15- to 24-year olds, two-thirds occurred among AGYW, and HIV and AIDS remain the leading cause of death among AGYW in this region (UNAIDS 2016a).

AGYW vulnerability to HIV is multifaceted - shaped by a range of proximal biological and behavioral factors, as well as more distal social and structural factors like gender norms (Harrison et al. 2015; Santelli et al. 2015). For instance, HIV incidence is higher when young women also have sexually transmitted infections (STIs) (Santelli et al. 2013). Behaviorally, engaging in transactional sex, having multiple partnerships, engaging in substance abuse, and limited condom use also contribute to HIV risk among AGYW (Jewkes et al. 2010; Santelli et al. 2013). Further, structural factors, like parental loss and being out-ofschool, are associated with HIV acquisition (Birdthistle et al. 2008). Prior research in Zambia, for instance, shows that gender inequality and poverty undermine HIV prevention among AGYW (Butts et al. 2017). Yet, each of these factors individually is not consistently associated with HIV acquisition among AGYW in different contexts (Napierala Mavedzenge et al. 2011). For instance, research in Malawi found that consistent condom use was not associated with HIV status among AGYW (Price et al. 2018). This complexity denotes the need to better assess the combination of factors that contribute to HIV risk among AGYW considering the multi-dimensionality of HIV risk among AGYW.

To stem the HIV epidemic among AGYW, HIV prevention program efforts need to reach AGYW who are most at risk of HIV acquisition. However, while AGYW's disproportionate risk is widely recognized, it is less clear which AGYW are most at risk (Price et al. 2018). The variability in risk factors across different contexts and the uneven distribution of risk creates confusion around how best to define HIV vulnerability for AGYW as well as challenges around whom to recruit into programs (Underwood et al. 2009). The current approach of segmenting AGYW by socio-demographic factors, like age and marital status, is often insufficient for differentiating HIV risk or vulnerability groups. For instance, targeting by marital status is common, yet research shows that it is not necessarily a risk factor for HIV acquisition. It also remains unclear whether the focus should be on individual-level behavioral factors, household-level characteristics, or broader structural factors in defining HIV vulnerability. Generating HIV vulnerability profiles based on factors that synergistically affect HIV and related outcomes among AGYW could be used by programmers for more effective targeting and assessment of HIV prevention efforts (Edelstein et al. 2013; Population Council 2015; Underwood and
Schwandt 2015). However, there is limited utilization of methods in sub-Saharan Africa that could assess underlying groupings of risk factors to develop segmented HIV vulnerability profiles of AGYW.

Another challenge faced by current efforts during program-level screening for HIV vulnerability among AGYW in a community is the potential to exacerbate stigma and discrimination (Denison et al. 2017). Going beyond sociodemographic segmentation, some efforts to reach the most at-risk young women are based on their sexual practices. A recent mapping of risk assessment tools to help identify/ enroll individuals at substantial risk of HIV infection found that key criteria for AGYW included socio-demographic characteristics (age of AGYW, age of sexual debut, age of partner), sexual behaviors (number of partners, condom use, transactional sex), and relationship characteristics (primary partner's HIV status or use of antiretroviral drugs), and exposure to violence (Dunbar et al. 2018). However, asking young women about sensitive topics like sexual activity, number of partners, coital frequency, and condom use in community settings where adolescent sexuality or HIV may already be stigmatized can subject young women to greater scrutiny and potentially lead to stigma and discrimination toward them. It may also deter young women from engaging in HIV prevention programs. Thus, the challenge remains to utilize information from non-sensitive questions to better identify HIV vulnerability.

This analysis explores whether underlying factors that influence proximate determinants of HIV risk (e.g., risky sexual behavior) could be used to define HIV vulnerability for AGYW (Boerma and Weir 2005). Using the proximate determinants theoretical framework, which highlights how underlying determinants can influence proximate determinants of HIV risk, we examine whether household characteristics and respondent characteristics, attitudes, and knowledge can be used to effectively define HIV vulnerability among AGYW (Boerma and Weir 2005; Santelli et al. 2015). In this paper, we provide empirically developed HIV vulnerability profiles for AGYW in three country contexts-Kenya, Malawi, and Zambia. We use latent class analysis (LCA), a mixed analytical model that aims to uncover unobserved heterogeneity in a population and to find substantively meaningful groups of people that are similar in their responses to measured variables (Muthén 2001, 2004). We use a range of low-sensitivity factors/ underlying determinants (that may be less likely to bring scrutiny and stigma toward AGYW) that may co-occur and reinforce AGYW's vulnerability and diminish their capacity and agency to enact preventative behaviors or practices. In each context, we assess the associations between the vulnerability profiles and HIV-related health outcomes. 


\section{Methods}

\section{Study population}

Cross-sectional survey data were collected with AGYW aged 15-24 years from eight study sites across Kenya, Malawi, and Zambia. In Kenya, the study sites included an urban and a peri-urban community in Kisumu County. In Malawi, the study sites included four rural sites in Zomba and Machinga districts. In Zambia, the study sites included two urban communities, one in the capital city of Lusaka and another in the central region of Ndola. These study sites were part of the U.S. President's Emergency Plan for AIDS Relief (PEPFAR)-supported DREAMS partnership program, focused on reducing HIV risk and incidence among AGYW and their male partners (Saul et al. 2018). DREAMS program locations were selected by PEPFAR in consultation with local government representatives and other stakeholders in each country. In general, the DREAMS program communities are characterized by high HIV prevalence rates among AGYW. The study sites were purposively selected, in consultation with PEPFAR colleagues and DREAMS implementing partners, to be representative of key geographic characteristics (e.g., urban/ rural) of DREAMS program communities in each country.

Eligible survey participants were females aged 15-24 years residing in the study catchment area, who intended to stay in the area for the subsequent year, and agreed to participate in the survey. In Kenya, 1014 out-ofschool AGYW were interviewed from October 2016 to February 2017. In Zambia, 846 out-of-school AGYW were interviewed from November 2016 to April 2017. In Malawi, 1653 out-of-school AGYW were interviewed from July 2017 to September 2017. Using the DREAMS program beneficiary rosters (in all three countries) and household listings (in Kenya and Zambia) for the program sites prepared by the program implementing partners, we conducted an age-stratified random sample to select potential respondents. Respondents were randomly sampled from participants who were enrolled in the DREAMS program and other AGYW residing in the catchment area of the study sites. Twenty respondents in Kenya, 33 in Zambia, and 3 in Malawi refused to participate due to lack of parental consent or limited time availability at the time of the interview.

Comprehensive surveys captured information on sociodemographic characteristics, sexual behaviors, partnership characteristics, social assets, and HIV outcomes (e.g., reported HIV status, STI symptoms, and HIV testing). The surveys were administered by trained female interviewers and conducted in a local language of the respondent's choosing (English, Kiswahili, Luo, and English in Kenya;
English, Bemba, or Nyanja in Zambia; and Chichewa and Yao in Malawi). Interviews were conducted in private yet convenient locations to the respondents (e.g., room in respondent's home, nearby field, or nearby community center), and out of earshot of parents, guardians, or other community members.

\section{Measures}

For the LCA model, we considered four key domains aiming to tap into underlying factors associated with HIV acquisition among AGYW: household characteristics, respondent characteristics, attitudes, and knowledge (Table 1).

Multilevel logistic regression models were used to validate the latent class solution or HIV risk profile, for different outcome variables (Table 2).

\section{Analysis}

LCA was used for HIV risk vulnerability classification. To decide the number of classes and best fit models, we used Akaike's information criterion (Akaike 1973, 1987), Bayesian information criterion (BIC) (Schwarz 1978), entropy (Celeux and Soromenho 1996), and the Lo-Mendell-Rubin likelihood ratio test (LMR test) (Lo et al. 2001). The LMR test was used to test the number of classes in this mixture analysis procedure; the former is obtained by running the $k$-class and $k-1$ class analyses and using the derivatives from both models to compute the $p$ value (a low $p$ value rejects the $k-1$ class model in favor of the k-class model) (Asparouhov and Muthén 2012). The classification quality of the model was evaluated according to the entropy criterion, in which the values range from zero to one, where values close to one indicate good classification. LCA was conducted using Mplus software (v6.12).

We examined four-, three-, and two-class models. The four- and three-class models did not fit the data well; thus, we focused analyses on the two-class models. The $p$-values of the LMR test supported the two-class solutions (Kenya: $p=0.032$; Zambia: $p=0.073$; Malawi: $p \leq 0.0001$ ) as the three-class solutions did not improve the model fit compared to the two-class solutions (all $p>0.10$ ). Furthermore, the best-fitting solutions, according to the BIC and ssaBIC values, were the two-class models for all three countries. The entropy values for the two-class models were $0.43,0.55$, and 0.48 , in Kenya, Zambia, and Malawi, respectively.

In order to validate the best latent class solution for HIV vulnerability (based on statistical and empirical evidence), the multilevel logistic regression models were used to assess associations between the derived vulnerability classes and different outcome variables (Table 2). The 
Table 1 Variables used in the latent class analysis to develop HIV risk profiles for out-of-school 15- to 24-year-old women in Kenya, Malawi, and Zambia, 2016-2017

\begin{tabular}{|c|c|}
\hline Domains and factors & Measurement and variable definition \\
\hline \multicolumn{2}{|l|}{ Household characteristics } \\
\hline Orphanhood & $\begin{array}{l}\text { Questions asked about loss of mother and father, defined as lost both parents, lost mother, lost father, and } \\
\text { non-orphan }\end{array}$ \\
\hline Household socioeconomic status & $\begin{array}{l}\text { Composite measure created of three questions about household construction, water, and sanitation } \\
\text { facilities and divided into tertiles of low, mid, and high }\end{array}$ \\
\hline Hunger in the past month & $\begin{array}{l}\text { Question about going without food for a whole day in the past month, defined as often/sometimes versus } \\
\text { rarely/never }\end{array}$ \\
\hline Adult supervision & $\begin{array}{l}\text { Questions asked whether an adult in the household knows the respondent's whereabouts during day or at } \\
\text { night, defined as yes versus no }\end{array}$ \\
\hline \multicolumn{2}{|l|}{ Respondent characteristics } \\
\hline Mobility & Question on movement or travel outside of community, defined as weekly/monthly, yearly, never \\
\hline Marital status & $\begin{array}{l}\text { Question asked about marital status (formal or civil or cohabitation as if married) of the respondents, } \\
\text { defined as currently married, formerly married, and never married }\end{array}$ \\
\hline \multicolumn{2}{|l|}{ Respondent attitudes } \\
\hline Support for gender equitable norms & $\begin{array}{l}\text { Attitudinal measures assessed support for gender equitable norms using the previously validated GEM } \\
\text { scale. The GEM scale assesses views on dimensions on home and child care (e.g., cooking and } \\
\text { cleaning are the wife's responsibility), sexual relationships (e.g., men are always ready to have sex), } \\
\text { health and disease prevention (e.g., my partner would be outraged if I asked him to use a condom), and } \\
\text { violence (e.g., there are times when a woman deserves to be beaten). An overall GEM scale score is } \\
\text { calculated and categorized as low, medium, and high support for equitable gender norms (Pulerwitz } \\
\text { and Barker 2008; Vu et al. 2017; Wesson et al. 2019) }\end{array}$ \\
\hline Perception on exposure to HIV & $\begin{array}{l}\text { Question on self-perception of HIV risk, "How likely is it that you have been exposed to HIV," defined } \\
\text { as (no risk/unlikely versus somewhat likely/very likely/don't know) (Santelli et al. 2013) }\end{array}$ \\
\hline \multicolumn{2}{|l|}{ Respondent knowledge } \\
\hline $\begin{array}{l}\text { Comprehensive knowledge about } \\
\text { HIV transmission }\end{array}$ & $\begin{array}{l}\text { Composite measure based on standard Demographic Health Survey questions of correct knowledge of } \\
\text { two ways to prevent HIV (e.g., can people reduce their chance of getting HIV by having just one } \\
\text { uninfected sex partner who has no other sex partners) and rejection of three misconceptions about HIV } \\
\text { (e.g., can people get the HIV/AIDS virus from mosquito bites), defined as yes/no }\end{array}$ \\
\hline $\begin{array}{l}\text { Comprehensive knowledge about } \\
\text { condoms }\end{array}$ & $\begin{array}{l}\text { Composite measure based on questions around correct knowledge that condoms are an effective method } \\
\text { of preventing pregnancy, protecting against HIV/AIDS, and protecting against STIs, defined as yes/no }\end{array}$ \\
\hline
\end{tabular}

multilevel regression models adjusted for the cluster structure (district level) of the data and age; robust standard errors were produced. All the regression analyses were performed in STATA 13.2 software.

\section{Ethics and consent}

Study protocols were reviewed and approved by the Population Council Institutional Review Board, as well by the Kenyatta National Hospital/University of Nairobi Ethics and Research Committee and National Commission for Science Technology and Innovation in Kenya; College of Medicine Research Ethics Committee at the University of Malawi in Malawi; ERES CONVERGE IRB and the National Health Research Authority in Zambia. Informed consent was obtained from all study participants (or parental consent and respondent assent, as appropriate). As per local ethical research guidelines, participants were compensated for their research participation: KSH300 (approximately US\$3) in Kenya, MWK1500 (approximately US\$2) in Malawi, and ZMW50 Kwacha (approximately US\$5) in Zambia.

\section{Results}

\section{Sample description}

Table 3 presents descriptive characteristics of the study samples from Kenya, Malawi, and Zambia. Mean age of survey respondents was 21 years across all three settings. Approximately $60 \%$ of AGYW in Kenya, $48 \%$ in Zambia, and $35 \%$ in Malawi had lost a parent or both. Marital status of the respondents differed by setting, 64\% of the respondents were currently married in Malawi, whereas half were in Kenya and only $19 \%$ in Zambia. About 36-40\% of the respondents reported being from households with low socio-economic status (SES) across all three settings. Over 
Table 2 Outcome variables used in the multilevel logistic regression models in Kenya, Malawi, and Zambia

\begin{tabular}{|c|c|}
\hline Self-reported HIV status & $\begin{array}{l}\text { Self-reported HIV status was asked as "what were the results of your HIV test or the last test } \\
\text { from which you received results?" with response options of HIV positive, HIV negative, } \\
\text { don't know, and never tested, defined as HIV positive versus other responses }\end{array}$ \\
\hline Experience of STI symptoms & $\begin{array}{l}\text { Composite measure that asked about experience with STI symptoms (e.g., painful urination, } \\
\text { genital ulcers) in the last } 6 \text { months, defined as yes to any symptom versus no to all }\end{array}$ \\
\hline Early age at sexual debut & Question on self-reported age at first sex, defined as $\leq 15$ years versus $\geq 16$ years \\
\hline Pregnancy experience & Question on any pregnancy experience by the partners, defined as yes versus no \\
\hline Multiple sexual partners in the last year & Question on the number of sexual partners in the last year, defined as $0 / 1$ versus $\geq 2$ \\
\hline Engaged in transactional sex & $\begin{array}{l}\text { Composite measure of a set of questions about having sex with any partner in the last } \\
12 \text { months because the respondent expected to receive or received money somewhere to } \\
\text { stay, or other material goods such as food or support for children, defined as yes to any } \\
\text { versus no to all }\end{array}$ \\
\hline $\begin{array}{l}\text { Experience of physical violence from intimate } \\
\text { partners in the last } 12 \text { months }\end{array}$ & $\begin{array}{l}\text { Composite measure from a set of questions that asked if AGYW experienced any of } \\
\text { following in the last } 12 \text { months: slapped or had something thrown at you which could hurt } \\
\text { you; pushed or shoved you; hit you with a fist or something else which could hurt you; } \\
\text { kicked, dragged, beaten, choked, or burnt you; and threatened to use or actually used a } \\
\text { gun, knife, or other weapon against you, defined as yes to any versus no to all }\end{array}$ \\
\hline $\begin{array}{l}\text { Experience of sexual violence from intimate } \\
\text { partners in the last } 12 \text { months }\end{array}$ & $\begin{array}{l}\text { Composite measure from a set of questions about sexual violence from an intimate partner } \\
\text { was defined as an AGYW experiencing any of following in the last } 12 \text { months: physically } \\
\text { forced into sex, threatened into sex, and forced to do any other sexual act versus no to all }\end{array}$ \\
\hline $\begin{array}{l}\text { Experience of sexual violence from non-partners } \\
\text { in the last } 12 \text { months }\end{array}$ & $\begin{array}{l}\text { Composite measure asking about AGYW experiencing any of the following in the last } \\
12 \text { months: forced or persuaded you to have sex against will, tried to force you to have sex, } \\
\text { forced to have sex while you were too drunk or drugged to refuse, and two or more men } \\
\text { forced you to have sex with them at the same time }\end{array}$ \\
\hline Condom use at last sex & Question about condom use at last sex with main partners, defined as yes versus no \\
\hline HIV testing in the last 12 months & Question about HIV testing in the last 12 months, defined as yes versus no \\
\hline
\end{tabular}

$20 \%$ of the AGYW in Kenya and Malawi had experienced hunger in the past month, whereas $13 \%$ in Zambia reported as such. Adult supervision was high, with $60-76 \%$ of AGYW reporting that an adult in their household knew where they were during the day or night. Mobility varied by setting, more than two-thirds of respondents in Kenya and Zambia reported being mobile, whereas only $20 \%$ of AGYW in Malawi reported traveling outside of their community in the past 12 months. Approximately a third of respondents in each setting had high support for gender equitable norms. In terms of HIV risk, 79\% in Kenya, 85\% in Zambia, and 53\% in Malawi did not think they were at risk of HIV acquisition. About half of the respondents in each setting did not have comprehensive knowledge about HIV, and over $70 \%$ in Kenya and Malawi and $49 \%$ in Zambia did not have comprehensive knowledge about condoms.

\section{Model fit statistics}

The fit statistics for each model solution are presented in Table 4 with two- and three-latent class solutions. To decide the best-fitting model solution for each country, we used a combination of the BIC, ssaBIC, and LMR $p$ value. The two-class solutions demonstrated the most meaningful class interpretation with adequate class sizes and were therefore selected as the best solutions to classify individuals into homogeneous groups for each of the countries.

\section{Higher and lower vulnerability profiles among AGYW}

Table 5 presents response probabilities by each of the latent classes for each country. We used a cut point of 0.4 to define a response probability as high. We defined class 1 as low HIV vulnerability profile and class 2 as high HIV vulnerability profile.

In Kenya, the higher HIV vulnerability profile comprised $34 \%$ of the sample, whereas the lower vulnerability profile comprised $66 \%$ of the sample. Distinguishing characteristics between the two profiles are that the high vulnerability profile had a higher probability of having a medium household SES, being hungry, not having adult supervision, having lower support for gender equitable norms, and having no comprehensive knowledge of HIV. Both the higher and lower vulnerability profile also had equally high probability of low mobility, being currently married, and having no comprehensive knowledge of condoms. 
Table 3 Descriptive characteristics of study sample, out-of-school 15- to 24-year-old women in Kenya, Malawi, and Zambia, 2016-2017

\begin{tabular}{|c|c|c|c|c|c|c|}
\hline \multirow{4}{*}{ Average age (SD) } & \multicolumn{2}{|c|}{ Kenya } & \multicolumn{2}{|c|}{ Malawi } & \multicolumn{2}{|c|}{ Zambia } \\
\hline & \multicolumn{2}{|c|}{$N=1014$} & \multicolumn{2}{|c|}{$N=1653$} & \multicolumn{2}{|c|}{$N=846$} \\
\hline & \multicolumn{2}{|c|}{$20.6(2.4)$} & \multicolumn{2}{|c|}{$20.7(2.3)$} & \multicolumn{2}{|c|}{$20.5(2.3)$} \\
\hline & $N$ & $\%$ & $N$ & $\%$ & $N$ & $\%$ \\
\hline \multicolumn{7}{|l|}{ Household characteristics } \\
\hline \multicolumn{7}{|l|}{ Orphanhood } \\
\hline Lost both mother and father & 230 & 22.7 & 130 & 7.9 & 108 & 12.8 \\
\hline Lost mother & 285 & 28.1 & 328 & 19.8 & 227 & 26.8 \\
\hline Lost father & 90 & 8.9 & 118 & 7.1 & 73 & 8.6 \\
\hline Not orphan & 409 & 40.3 & 1077 & 65.2 & 438 & 51.8 \\
\hline \multicolumn{7}{|l|}{ Household socioeconomic status } \\
\hline Low & 368 & 36.3 & 664 & 40.2 & 308 & 36.4 \\
\hline Medium & 339 & 33.4 & 551 & 33.3 & 363 & 42.9 \\
\hline High & 307 & 30.3 & 438 & 26.5 & 175 & 20.7 \\
\hline \multicolumn{7}{|l|}{ Hunger in the past month } \\
\hline Often/Sometimes & 245 & 24.2 & 368 & 22.3 & 111 & 13.1 \\
\hline Rarely/never & 769 & 75.8 & 1285 & 77.7 & 735 & 86.9 \\
\hline \multicolumn{7}{|l|}{ Adult supervision } \\
\hline No & 302 & 29.8 & 243 & 24.3 & 324 & 38.3 \\
\hline Yes & 712 & 70.2 & 1252 & 75.7 & 522 & 61.7 \\
\hline \multicolumn{7}{|l|}{ Respondent characteristics } \\
\hline \multicolumn{7}{|l|}{ Mobility } \\
\hline Weekly/monthly & 125 & 12.3 & 288 & 17.4 & 244 & 28.8 \\
\hline Yearly & 555 & 54.7 & 18 & 1.1 & 321 & 37.9 \\
\hline No mobility & 334 & 32.9 & 1347 & 81.5 & 281 & 33.2 \\
\hline \multicolumn{7}{|l|}{ Marital status } \\
\hline Currently married & 511 & 50.4 & 1049 & 63.5 & 159 & 18.8 \\
\hline Formerly married & 54 & 5.3 & 263 & 15.9 & 50 & 5.9 \\
\hline Never married & 449 & 44.3 & 341 & 20.6 & 637 & 75.3 \\
\hline \multicolumn{7}{|l|}{ Respondent attitudes } \\
\hline \multicolumn{7}{|l|}{ Support for gender equitable norms } \\
\hline Low & 386 & 38.1 & 550 & 33.3 & 333 & 39.4 \\
\hline Moderate & 329 & 32.4 & 551 & 33.3 & 285 & 33.7 \\
\hline High & 299 & 29.5 & 552 & 33.4 & 228 & 27.0 \\
\hline \multicolumn{7}{|l|}{ Perception on exposure to $H I V$} \\
\hline Somewhat likely/don't know/high risk & 210 & 20.7 & 782 & 47.3 & 127 & 15.0 \\
\hline No risk/unlikely & 804 & 79.3 & 871 & 52.7 & 719 & 85.0 \\
\hline \multicolumn{7}{|l|}{ Respondent knowledge } \\
\hline \multicolumn{7}{|c|}{ Comprehensive knowledge about HIV transmission } \\
\hline No & 444 & 43.8 & 861 & 52.1 & 423 & 50 \\
\hline Yes & 570 & 56.2 & 792 & 47.9 & 423 & 50 \\
\hline \multicolumn{7}{|l|}{ Comprehensive knowledge about condoms } \\
\hline No & 746 & 73.6 & 1190 & 72 & 413 & 48.8 \\
\hline Yes & 268 & 26.4 & 463 & 28 & 433 & 51.2 \\
\hline
\end{tabular}

In Malawi, the higher and lower vulnerability profile comprised $53 \%$ and $47 \%$ of the sample, respectively. Both profiles had high probability of being currently married, high self-perceived risk of HIV exposure, and no comprehensive knowledge of condoms but had low probability of being mobile and being a double orphan. Distinguishing characteristics between the two profiles are that the higher vulnerability profile had high probability of low support for gender equitable norms, medium household SES, and no comprehensive knowledge of HIV. 
Table 4 Latent class analysis fit indices for two- and three-class solutions among study samples of out-of-school 15- to 24-yearold women in Kenya, Malawi, and Zambia, 2016-2017

\begin{tabular}{llllllrr}
\hline Study sample & Class & AIC & BIC & ssaBIC & Entropy & LMR value & $p$ value \\
\hline Kenya & 2 & $16,586.75$ & $16,749.17$ & $16,644.36$ & 0.432 & 136.47 & 0.0326 \\
& 3 & $16,563.88$ & $16,809.97$ & $16,651.16$ & 0.509 & 56.39 & 0.5653 \\
\multirow{2}{*}{ Malawi } & 2 & $24,966.85$ & $25,145.39$ & $25,040.56$ & 0.483 & 419.78 & $<0.0001$ \\
& 3 & $24,926.04$ & $25,196.55$ & $25,037.71$ & 0.489 & 74.23 & 0.7738 \\
Zambia & 2 & $13,425.29$ & $13,581.73$ & $13,476.93$ & 0.552 & 111.85 & 0.0735 \\
& 3 & $13,418.41$ & $13,655.43$ & $13,496.65$ & 0.582 & 40.54 & 0.5739 \\
\hline
\end{tabular}

AIC Akaike information criterion, BIC Bayesian information criterion, ssaBIC sample size adjusted, LMR Lo-Mendell-Rubin value

Table 5 Higher and lower vulnerability profiles of out-of-school 15- to 24-year-old women in Kenya, Malawi, and Zambia, 2016-2017

\begin{tabular}{|c|c|c|c|c|c|c|}
\hline \multirow[t]{2}{*}{ Indicator } & \multicolumn{2}{|l|}{ Kenya } & \multicolumn{2}{|l|}{ Malawi } & \multicolumn{2}{|l|}{ Zambia } \\
\hline & $\begin{array}{l}\text { Class } 2 \\
\text { Higher } \\
\text { vulnerability }\end{array}$ & $\begin{array}{l}\text { Class } 1 \\
\text { Lower } \\
\text { vulnerability }\end{array}$ & $\begin{array}{l}\text { Class } 1 \\
\text { Higher } \\
\text { vulnerability }\end{array}$ & $\begin{array}{l}\text { Class } 2 \\
\text { Lower } \\
\text { vulnerability }\end{array}$ & $\begin{array}{l}\text { Class } 1 \\
\text { Higher } \\
\text { vulnerability }\end{array}$ & $\begin{array}{l}\text { Class } 2 \\
\text { Lower } \\
\text { vulnerability }\end{array}$ \\
\hline Lost both mother and father & 0.33 & 0.17 & 0.06 & 0.10 & 0.13 & 0.12 \\
\hline Lost mother & 0.26 & 0.29 & 0.21 & 0.18 & 0.27 & 0.27 \\
\hline Lost father & 0.10 & 0.09 & 0.08 & 0.06 & 0.09 & 0.08 \\
\hline $\begin{array}{l}\text { Low household socioeconomic } \\
\text { status }\end{array}$ & 0.27 & 0.41 & 0.26 & 0.56 & 0.36 & 0.37 \\
\hline $\begin{array}{l}\text { Medium household socioeconomic } \\
\text { status }\end{array}$ & 0.46 & 0.27 & 0.46 & 0.19 & 0.4 & 0.46 \\
\hline $\begin{array}{l}\text { Hunger in the past month } \\
\text { (often/sometimes) }\end{array}$ & 0.44 & 0.14 & 0.31 & 0.13 & 0.16 & 0.09 \\
\hline No adult supervision & 0.44 & 0.22 & 0.36 & 0.12 & 0.43 & 0.32 \\
\hline High mobility (weekly/monthly) & 0.19 & 0.09 & 0.12 & 0.24 & 0.28 & 0.31 \\
\hline Low mobility (yearly) & 0.57 & 0.54 & 0.01 & 0.01 & 0.31 & 0.47 \\
\hline Currently married & 0.62 & 0.44 & 0.69 & 0.58 & 0.22 & 0.14 \\
\hline Formerly married & 0.08 & 0.04 & 0.17 & 0.15 & 0.06 & 0.06 \\
\hline $\begin{array}{l}\text { Lower support for gender } \\
\text { equitable norms }\end{array}$ & 0.68 & 0.23 & 0.52 & 0.13 & 0.68 & 0.01 \\
\hline $\begin{array}{l}\text { Moderate support for gender } \\
\text { equitable norms }\end{array}$ & 0.25 & 0.36 & 0.35 & 0.32 & 0.24 & 0.47 \\
\hline $\begin{array}{l}\text { High perceived risk of exposure to } \\
\text { HIV }\end{array}$ & 0.34 & 0.14 & 0.51 & 0.43 & 0.12 & 0.19 \\
\hline $\begin{array}{l}\text { No comprehensive knowledge of } \\
\text { HIV }\end{array}$ & 0.58 & 0.36 & 0.76 & 0.25 & 0.64 & 0.31 \\
\hline $\begin{array}{l}\text { No comprehensive knowledge of } \\
\text { condoms }\end{array}$ & 0.73 & 0.74 & 0.84 & 0.59 & 0.57 & 0.37 \\
\hline Class probability & 0.34 & 0.66 & 0.53 & 0.47 & 0.57 & 0.43 \\
\hline Classification of individuals $(\%, N)$ & $32.2(327)$ & $67.8(687)$ & $53.0(876)$ & 47.0 (777) & $51.5(436)$ & $48.5(410)$ \\
\hline
\end{tabular}

Bold values denote the key distinguishing characteristic of the latent class profile

In Zambia, the higher and lower vulnerability profile comprised $57 \%$ and $42 \%$ of the sample, respectively. Both profiles had low probability of being currently married, experiencing hunger, and having high self-perceived risk of exposure to HIV, but high probability of having low or medium household SES. Distinguishing characteristics between the two profiles are that the higher vulnerability profile had higher probability of no adult supervision, lower support for gender equitable norms, and no comprehensive knowledge of HIV and condoms.

\section{Association between HIV vulnerability profiles and HIV status, and key sexual and reproductive health (SRH) outcomes}

Table 6 presents multivariate regression results examining associations between AGYW's HIV vulnerability profiles, 
HIV status, and key SRH outcomes, after adjusting for site and age. In all three settings, being in the higher vulnerability class compared to the lower vulnerability class was associated with a range for poor SRH and HIV outcomes among AGYW. In Kenya, AGYW who were in the higher vulnerability class were at significantly greater risk of already living with HIV and had significantly greater odds of having experienced STI symptoms in the past six months, a very early sexual debut, a pregnancy, multiple sexual partners in the past year, physical and sexual violence from intimate partners, and sexual violence from non-intimate partners. Being in the high vulnerability class was also marginally associated with engaging in transactional sex.

In Malawi, being in the higher vulnerability class was associated with increased odds of having experienced STI symptoms, very early sexual debut, and pregnancy. Being in the high vulnerability class was also marginally associated with engaging in transactional sex, and experience of physical violence from intimate partners and sexual violence from non-partners.

In Zambia, AGYW in the higher vulnerability class had increased risk of engaging in transactional sex and increased odds of very early sexual debut, having a pregnancy experience, experiencing physical and sexual violence from intimate partners, and had lower odds of condom use at last sex. There were no significant associations with recent HIV testing and vulnerability profiles in any setting.

\section{Discussion}

We use quantitative data gathered with over 3000 AGYW from three country contexts tapping individual- and household-level factors to identify distinct profiles of HIV vulnerability among AGYW. This multi-country analysis shows that even in communities with high HIV prevalence, not all AGYW are equally at risk of HIV. We find two distinct profiles of HIV vulnerability (higher and lower) among out-of-school AGYW in Kenya, Malawi, and Zambia. Using less-sensitive questions, which measure individual and social factors more distally associated with HIV risk, this analysis identifies profiles of AGYW who are more vulnerable to HIV in high HIV prevalence settings. This analysis contributes knowledge toward the key challenge of identifying and reaching vulnerable AGYW for HIV prevention efforts, as being in the higher vulnerability profile was associated with a range of poor SRH outcomes that are proximally related to HIV acquisition. This segmenting approach provides a more nuanced understanding of factors that synergistically constitute higher vulnerability for out-of-school AGYW in each country context, and it offers the possibility for initiating a conversation about risk and could potentially lead to the development of more effective targeting of subgroups of young women who need to be urgently reached with HIV prevention programming.

In our analysis, we find that some factors that define vulnerability are context specific, while others consistently contribute to HIV vulnerability across settings. In urban/ peri-urban Kenya for instance, being hungry/food insecurity-which has been linked with increased sexual risk and inability to negotiate safe sexual practices (Chop et al. 2017) — contributed to the higher HIV vulnerability profile, whereas this was not the case in Malawi or Zambia. In our analysis, parental supervision was also a contributing factor for vulnerability in urban/peri-urban Kenya and urban Zambia. Recent research in Kenya and the region has shown that family connectedness and parental monitoring were associated with less sexual risk taking (Cluver et al. 2016; Wachira et al. 2019). In both Kenya and Malawi, coming from a household that did not have the poorest or the richest SES relative to the community was also a key factor in vulnerability. In the fairly impoverished communities in our study, it could mean that a medium socioeconomic status household may not have access to social support structures available to the poorest households. Prior research in Malawi has also shown a similar relationship between household SES and HIV and found that young people living in comparatively better off households/areas are more likely to have HIV, likely due to their proximity to roads and mobile populations (Mensch and Soler-Hampejsek 2017). Across the three country contexts, having gender inequitable attitudes and no comprehensive knowledge about HIV were consistently associated with the higher vulnerability profile. The prominent influence of these factors in defining the higher vulnerability profile across all three contexts may mean that these may be essential elements for HIV prevention programming to focus on/consider. Prior research has demonstrated the link between inequitable gender norms and sexual risk behaviors (Gottert et al. 2018). Recent research among AGYW in the region has shown that having inequitable gender attitudes had the highest predicted probability of HIV acquisition (Wesson et al. 2019). Similarly, comprehensive sexuality education, particularly programs that take an empowerment approach and discuss gender and power, has been shown to be associated with lower risk-taking behaviors (Boonstra 2015; Haberland and Rogow 2015). The persistence of these two factors in defining the higher vulnerability profile signals the need for greater attention to these factors collectively in intervention design and messaging. For instance, ensuring comprehensive knowledge about HIV transmission and condoms among AGYW, and addressing gender roles and norms at 
Table 6 Multivariate associations between HIV vulnerability profiles and HIV status, and sexual and reproductive health outcomes among outof-school 15- to 24-year-old women, Kenya, Malawi, and Zambia, 2016-2017

\begin{tabular}{|c|c|c|c|c|c|c|c|c|c|}
\hline & \multicolumn{3}{|c|}{ Kenya $(N=1014)$} & \multicolumn{3}{|c|}{ Malawi $(N=1653)$} & \multicolumn{3}{|c|}{ Zambia $(N=846)$} \\
\hline & \multicolumn{3}{|c|}{ HIV vulnerability profile } & \multicolumn{3}{|c|}{ HIV vulnerability profile } & \multicolumn{3}{|c|}{ HIV vulnerability profile } \\
\hline & $\begin{array}{l}\text { Low HIV } \\
\text { vulnerability }\end{array}$ & $\begin{array}{l}\text { High HIV } \\
\text { vulnerability }\end{array}$ & $p$ value & $\begin{array}{l}\text { Low HIV } \\
\text { vulnerability }\end{array}$ & $\begin{array}{l}\text { High HIV } \\
\text { vulnerability }\end{array}$ & $p$ value & $\begin{array}{l}\text { Low HIV } \\
\text { vulnerability }\end{array}$ & $\begin{array}{l}\text { High HIV } \\
\text { vulnerability }\end{array}$ & $p$ value \\
\hline HIV positive (\%) & 3.8 & 11.3 & & 1.3 & 2.1 & & 2.7 & 3.2 & \\
\hline AOR $(95 \% \mathrm{CI})$ & Ref & $\begin{array}{l}2.75 \\
\quad(1.62-4.67)\end{array}$ & $<0.001$ & Ref & $\begin{array}{l}1.61 \\
\quad(0.74-3.51)\end{array}$ & 0.230 & Ref & $\begin{array}{l}1.25 \\
(0.56-2.79)\end{array}$ & 0.586 \\
\hline $\begin{array}{l}\text { Sexually } \\
\text { transmitted } \\
\text { infection } \\
\text { symptoms }(\%)\end{array}$ & 18.8 & 26.9 & & 26.4 & 34.4 & & 14.9 & 14.9 & \\
\hline $\operatorname{AOR}(95 \% \mathrm{CI})$ & Ref & $\begin{array}{l}1.57 \\
(1.14-2.15)\end{array}$ & 0.005 & Ref & $\begin{array}{l}1.44 \\
\quad(1.16-1.78)\end{array}$ & 0.001 & Ref & $\begin{array}{l}1.00 \\
(0.68-1.47)\end{array}$ & 0.99 \\
\hline $\begin{array}{l}\text { First } \\
\text { sex } \leq 15 \text { years } \\
(\%) \\
\begin{array}{l}\text { Kenya }=896 \\
\text { Malawi }=1569 \\
\text { Zambia }=626)\end{array}\end{array}$ & 37.4 & 47.7 & & 30.1 & 34.9 & & 11.4 & 22.3 & \\
\hline AOR $(95 \%$ CI) & Ref & $\begin{array}{l}1.73 \\
(1.29-2.31)\end{array}$ & $<0.001$ & Ref & $\begin{array}{l}1.24 \\
\quad(1.00-1.54)\end{array}$ & 0.046 & Ref & $\begin{array}{l}2.15 \\
\quad(1.37-3.37)\end{array}$ & 0.001 \\
\hline $\begin{array}{l}\text { Pregnancy } \\
\text { experience }(\%)\end{array}$ & 67 & 89.9 & & 82.5 & 90.4 & & 40.2 & 52.1 & \\
\hline AOR $(95 \% \mathrm{CI})$ & Ref & $\begin{array}{l}3.71 \\
\quad(2.45-5.61)\end{array}$ & $<0.001$ & Ref & $\begin{array}{l}2.19 \\
\quad(1.63-2.95)\end{array}$ & $<0.001$ & Ref & $\begin{array}{l}2.03 \\
\quad(1.50-2.74)\end{array}$ & $<0.001$ \\
\hline $\begin{array}{l}\text { Engaged in } \\
\text { transactional sex } \\
(\%) \\
(\text { Kenya }=930 ; \\
\text { Malawi }=1569 ; \\
\text { Zambia }=628)\end{array}$ & 5.2 & 7.9 & & 2.5 & 4.4 & & 3.4 & 8.6 & \\
\hline $\operatorname{AOR}(95 \% \mathrm{CI})$ & Ref & $\begin{array}{l}1.72 \\
(0.99-2.97)\end{array}$ & 0.054 & Ref & $\begin{array}{l}1.74 \\
(0.98-3.10)\end{array}$ & 0.058 & Ref & $\begin{array}{l}2.66 \\
(1.27-5.57)\end{array}$ & 0.009 \\
\hline $\begin{array}{l}\text { Multiple sexual } \\
\text { partners }(\%) \\
(\text { Kenya }=675 ; \\
\text { Malawi }=1192 ; \\
\text { Zambia }=360)\end{array}$ & 11.6 & 24.7 & & 15.4 & 17.4 & & 4.9 & 8.7 & \\
\hline $\operatorname{AOR}(95 \% \mathrm{CI})$ & Ref & $\begin{array}{l}2.75 \\
\quad(1.79-4.22)\end{array}$ & $<0.001$ & Ref & $\begin{array}{l}1.16 \\
(0.84-1.60)\end{array}$ & 0.357 & Ref & $\begin{array}{l}1.84 \\
(0.77-4.38)\end{array}$ & 0.17 \\
\hline $\begin{array}{l}\text { HIV test in the past } \\
12 \text { months }(\%)\end{array}$ & 94.8 & 96 & & 93.1 & 96.5 & & 70 & 70.4 & \\
\hline $\operatorname{AOR}(95 \% \mathrm{CI})$ & Ref & $\begin{array}{l}1.16 \\
(0.60-2.24)\end{array}$ & 0.661 & Ref & $\begin{array}{l}1.04 \\
\quad(0.94-1.14)\end{array}$ & 0.484 & Ref & $\begin{array}{l}1.10 \\
(0.81-1.48)\end{array}$ & 0.555 \\
\hline $\begin{array}{l}\text { Condom use at last } \\
\text { sex }(\%) \\
(\text { Kenya }=675 \\
\text { Malawi }=1439 \\
\text { Zambia }=324)\end{array}$ & 34 & 30.5 & & 16.9 & 18.6 & & 43.3 & 27 & \\
\hline AOR $(95 \%$ CI) & Ref & $\begin{array}{l}0.91 \\
\quad(0.64-1.29)\end{array}$ & 0.6 & Ref & $\begin{array}{l}1.11 \\
\quad(0.84-1.46)\end{array}$ & 0.448 & Ref & $\begin{array}{l}0.45 \\
\quad(0.28-0.72)\end{array}$ & 0.001 \\
\hline
\end{tabular}


Table 6 (continued)

\begin{tabular}{|c|c|c|c|c|c|c|c|c|c|}
\hline & \multicolumn{3}{|c|}{ Kenya $(N=1014)$} & \multicolumn{3}{|c|}{ Malawi $(N=1653)$} & \multicolumn{3}{|c|}{ Zambia $(N=846)$} \\
\hline & \multicolumn{3}{|c|}{ HIV vulnerability profile } & \multicolumn{3}{|c|}{ HIV vulnerability profile } & \multicolumn{3}{|c|}{ HIV vulnerability profile } \\
\hline & $\begin{array}{l}\text { Low HIV } \\
\text { vulnerability }\end{array}$ & $\begin{array}{l}\text { High HIV } \\
\text { vulnerability }\end{array}$ & $p$ value & $\begin{array}{l}\text { Low HIV } \\
\text { vulnerability }\end{array}$ & $\begin{array}{l}\text { High HIV } \\
\text { vulnerability }\end{array}$ & $p$ value & $\begin{array}{l}\text { Low HIV } \\
\text { vulnerability }\end{array}$ & $\begin{array}{l}\text { High HIV } \\
\text { vulnerability }\end{array}$ & $p$ value \\
\hline $\begin{array}{l}\text { Experienced sexual } \\
\text { violence from } \\
\text { intimate partners } \\
(\%) \\
(\text { Kenya }=684 ; \\
\text { Malawi }=1561 ; \\
\text { Zambia }=654)\end{array}$ & 12.8 & 29.5 & & 16.5 & 19 & & 18.5 & 30.3 & \\
\hline $\operatorname{AOR}(95 \% \mathrm{CI})$ & Ref & $\begin{array}{l}2.79 \\
\quad(1.87-4.17)\end{array}$ & $<0.001$ & Ref & $\begin{array}{l}1.12 \\
\quad(0.86-1.46)\end{array}$ & 0.417 & & $\begin{array}{l}1.90 \\
(1.32-2.74)\end{array}$ & 0.001 \\
\hline $\begin{array}{l}\text { Experienced of } \\
\text { physical violence } \\
\text { from intimate } \\
\text { partners }(\%) \\
(\text { Kenya }=684 ; \\
\text { Malawi }=1561 ; \\
\text { Zambia }=654)\end{array}$ & 23.8 & 43.3 & & 14.7 & 17.3 & & 21.8 & 37.3 & \\
\hline $\operatorname{AOR}(95 \% \mathrm{CI})$ & Ref & $\begin{array}{l}2.31 \\
\quad(1.62-3.30)\end{array}$ & $<0.001$ & Ref & $\begin{array}{l}1.26 \\
(0.95-1.66)\end{array}$ & 0.1 & & $\begin{array}{l}2.21 \\
\quad(1.56-3.12)\end{array}$ & $<0.001$ \\
\hline $\begin{array}{l}\text { Experienced sexual } \\
\text { violence from } \\
\text { non-intimate } \\
\text { partners }(\%)\end{array}$ & 16.9 & 26.9 & & 7.9 & 10.4 & & 17.6 & 15.1 & \\
\hline $\operatorname{AOR}(95 \% \mathrm{CI})$ & Ref & $\begin{array}{l}1.94 \\
\quad(1.40-2.69)\end{array}$ & $<0.001$ & Ref & $\begin{array}{l}1.36 \\
(0.95-1.92)\end{array}$ & 0.087 & & $\begin{array}{l}0.83 \\
\quad(0.57-1.20)\end{array}$ & 0.315 \\
\hline
\end{tabular}

AOR Adjusted odds ratios. All regression estimates are based on multilevel model and adjusted for the cluster structure (district) and age

the individual and community levels could shift HIV vulnerability for AGYW.

Our study uses the segmentation approach (Sgaier et al. 2018) to identify HIV vulnerability profiles for AGYW living in sub-Saharan Africa. While segmentation approaches have long been used in business and marketing fields, their application in global public health efforts remains limited (Gomez et al. 2018). Notable exceptions include a study in Malawi that examined HIV risk perception and self-efficacy dimensions to better inform the development of tailored HIV prevention messages to different subgroups of men and women (Rimal et al. 2009), work in Zambia and Zimbabwe on understanding the underlying drivers for men's decisions for voluntary medical male circumcision, and work in Niger around developing profiles of women's willingness to adopt family planning (Camber Collective 2015; Dalglish et al. 2018). To-date, segmentation using LCA has been used only sparingly in HIV research in subSaharan Africa, a region with the highest HIV burden, and where this approach may offer critical insights around HIV vulnerability and improved targeting. This analysis is an initial attempt at the application of such an approach across three countries and adds new knowledge to this burgeoning field.

We conducted this examination to assess whether nonsensitive questions could be used to define HIV vulnerability profiles among out-of-school AGYW. The LCA allowed us to look at the set of factors that together/synergistically constitute higher vulnerability in each country context, and regression analyses confirmed that AGYW in the higher vulnerability profile in each country were more likely to be engaging in a range of risky behaviors, and subject to sexual violence compared to AGYW in the lower vulnerability profile_-putting them at greater risk of HIV acquisition. A next step would be to translate these findings for use in HIV prevention program screening tools. Since our analysis used a set of non-sensitive measures to assess HIV vulnerability, these measures could be captured and used at the community level. Some of the items used in our analysis (e.g., GEM scale) would need to be pared down for ease of use and interpretation. This type of segmentation analysis could also lead to better programmatic evaluations. Subsequent work can assess whether AGYW in the higher vulnerability profiles have increased exposure and uptake of program interventions, whether there is a shift in 
the vulnerability profile, and whether there are changes in risk behaviors among AGYW in the high vulnerability group. From a policy perspective, we hope this study highlights for the global health and development sector practitioners and donors the need for more effective segmentation or profiling of target audiences for intervention design and implementation.

Our study has some limitations. Self-reported data from AGYW may be subject to bias. AGYW may have underreported/may not have disclosed their HIV status. Our study inclusion criteria (e.g., intention to stay in the area) could also be introducing bias. This analysis also relies on cross-sectional data, and therefore outcomes, such as sexual violence, are reported retrospectively. This analysis presents an initial step in applying a segmentation approach for outreach in HIV prevention programming but may have applicability in other public health sectors as well. Future work should assess whether these profiles and this approach is useful for targeting highly vulnerable girls in HIV prevention programming and evaluation efforts. Subsequent examinations could consider stratifications by age or marital status for refinement of vulnerability profiles. These profiles could be considered in similar contexts within Kenya, Malawi, and Zambia among out-of-school AGYW. Additional work is needed to examine whether these findings could be generalized to other contexts or to develop context-specific vulnerability profiles.

\section{Conclusion}

To stem the HIV epidemic, HIV prevention programs need to reach the right people with the right interventions. It is often a challenge to identify whom to reach in high HIV prevalence settings and to identify HIV vulnerability. We found two distinct profiles of risk among out-of-school AGYW, defined by a grouping of factors that synergistically influence HIV vulnerability. Our analysis found that AGYW in the higher vulnerability class had increased odds of negative health outcomes and experiences, confirming that the higher and lower vulnerability profiles are distinct. These analyses provide insights on the need to tailor community-based HIV prevention efforts by differentially targeting/tailoring interventions and health services for subpopulations in higher versus lower HIV vulnerability profiles.

Acknowledgements The authors would like to acknowledge the DREAMS program participants and implementing partners in Kenya (Aphia Plus/PATH, I Choose Life, Make Me Smile), Malawi (OneC), and Zambia (PACT, CMMB, Marie Stopes Zambia), and our research team coordinators and data collectors for their support during the data collection. We would like to acknowledge support from
Population Council colleagues who provided support in the preparation of this manuscript.

Funding Funding support for the Kenya and Zambia studies was provided by the Bill \& Melinda Gates Foundation (OPP1136778, DREAMS Implementation Science Research). Funding for the Malawi study was provided by the generous support of the American people through the United States President's Emergency Plan for AIDS Relief (PEPFAR) and the United States Agency for International Development (USAID) under Project SOAR (Cooperative Agreement AID-OAA-A-14-00060). The contents of this manuscript are the sole responsibility of the authors and do not necessarily reflect the views of PEPFAR, USAID, or the United States Government.

\section{Compliance with ethical standards}

Conflict of interest The authors declare no conflicts of interest.

Ethical approval Ethical approval of the study protocol was obtained by the Population Council Institutional Review Board (protocol \# 744 and 745), as well by the Kenyatta National Hospital/University of Nairobi Ethics (P384/05/2016) and Research Committee and National Commission for Science Technology and Innovation in Kenya; College of Medicine Research Ethics Committee at the University of Malawi in Malawi (PP.01/17/2095); ERES CONVERGE IRB (2016May-016) and the National Health Research Authority in Zambia.

Open Access This article is licensed under a Creative Commons Attribution 4.0 International License, which permits use, sharing, adaptation, distribution and reproduction in any medium or format, as long as you give appropriate credit to the original author(s) and the source, provide a link to the Creative Commons licence, and indicate if changes were made. The images or other third party material in this article are included in the article's Creative Commons licence, unless indicated otherwise in a credit line to the material. If material is not included in the article's Creative Commons licence and your intended use is not permitted by statutory regulation or exceeds the permitted use, you will need to obtain permission directly from the copyright holder. To view a copy of this licence, visit http://creativecommons. org/licenses/by/4.0/.

\section{References}

Akaike H (ed) (1973) Information theory and an extension of the maximum likelihood principle. Akadémiai Kiadó, Budapest

Akaike H (1987) Factor analysis and AIC. Psychometrika 52:317-332. https://doi.org/10.1007/bf02294359

Asparouhov T, Muthén B (2012) Using Mplus TECH11 and TECH14 to test the number of latent classes. Mplus Web Notes 14:22

Birdthistle IJ, Floyd S, Machingura A, Mudziwapasi N, Gregson S, Glynn JR (2008) From affected to infected? Orphanhood and HIV risk among female adolescents in urban Zimbabwe. Aids 22:759-766. https://doi.org/10.1097/QAD.0b013e3282f4cac7

Boerma JT, Weir SS (2005) Integrating demographic and epidemiological approaches to research on HIV/AIDS: the proximatedeterminants framework. J Infect Dis 191(Suppl 1):S61-S67. https://doi.org/10.1086/425282

Boonstra HD (2015) Advancing sexuality education in developing countries. In: Evidence-based approaches to sexuality education: a global perspective. p 346 
Butts SA, Parmley LE, Alcaide ML et al (2017) Let us fight and support one another: adolescent girls and young women on contributors and solutions to HIV risk in Zambia. Int J Womens Health 9:727-737. https://doi.org/10.2147/IJWH.S142232

Camber Collective (2015) Increasing contraceptive use in Niger: project recapitulation. https://static1.squarespace.com/static/ 55723b6be4b05ed81f077108/t/566712fe05f8e2d4918a0acf/ 1449595646623/Niger+FP_Project+Recapitulation.pdf

Celeux G, Soromenho G (1996) An entropy criterion for assessing the number of clusters in a mixture model. J Classif 13:195-212. https://doi.org/10.1007/bf01246098

Chop E, Duggaraju A, Malley A et al (2017) Food insecurity, sexual risk behavior, and adherence to antiretroviral therapy among women living with HIV: a systematic review. Health Care Women Int 38:927-944. https://doi.org/10.1080/07399332.2017. 1337774

Cluver LD, Orkin FM, Yakubovich AR, Sherr L (2016) Combination social protection for reducing HIV-risk behavior among adolescents in South Africa. J Acquir Immune Defic Syndr 72:96-104. https://doi.org/10.1097/QAI.0000000000000938

Dalglish SL, Vandermark J, Rossier C, Kemou A, Neighbor H (2018) Using marketing science to understand contraceptive demand in high-fertility Niger. Stud Fam Plan 49:367-383. https://doi.org/ 10.1111/sifp. 12078

Denison JA, Pettifor A, Mofenson LM et al (2017) Youth engagement in developing an implementation science research agenda on adolescent HIV testing and care linkages in sub-Saharan Africa. AIDS 31(Suppl 3):S195-S201. https://doi.org/10.1097/QAD. 0000000000001509

Dunbar MS, Donaldson E, Gomez A, Clancy J, Warren M, Gardiner E (2018) Risk assessment tools and the identification of individuals at high-risk of HIV infection in the delivery of oral PrEP. In: Paper presented at the HIVR4P. Madrid

Edelstein ZR, Schulyer AC, Helleringer S et al (2013) 011.6 migration and HIV risk in Rakai Youth, 2000-2010. Sex Transm Infect 89:A48. https://doi.org/10.1136/sextrans-2013-051184. 0148

Gomez A, Loar R, Kramer AE (2018) The impact of market segmentation and social marketing on uptake of preventive programmes: the example of voluntary medical male circumcision. A literature review [version 1; peer review: 2 approved, 1 approved with reservations]. Gates Open Res. https://doi.org/10. 12688/gatesopenres.12888.1

Gottert A, Barrington C, McNaughton-Reyes HL et al (2018) Gender norms, gender role conflict/stress and HIV risk behaviors among men in Mpumalanga, South Africa. AIDS Behav 22:1858-1869. https://doi.org/10.1007/s10461-017-1706-9

Haberland N, Rogow D (2015) Sexuality education: emerging trends in evidence and practice. J Adolesc Health 56:S15-S21. https:// doi.org/10.1016/j.jadohealth.2014.08.013

Harrison A, Colvin CJ, Kuo C, Swartz A, Lurie M (2015) Sustained high HIV incidence in young women in Southern Africa: social, behavioral, and structural factors and emerging intervention approaches. Curr HIV/AIDS Rep 12:207-215. https://doi.org/10. 1007/s11904-015-0261-0

Jewkes RK, Dunkle K, Nduna M, Shai N (2010) Intimate partner violence, relationship power inequity, and incidence of HIV infection in young women in South Africa: a cohort study. Lancet 376(9734):41-48. https://doi.org/10.1016/S01406736(10)60548-X

Lo Y, Mendell NR, Rubin DB (2001) Testing the number of components in a normal mixture. Biometrika 88:767-778

Mensch B, Soler-Hampejsek E (2017) Characteristics associated with HIV and HSV-2 among adolescents in Malawi. In: Project SOAR results brief. Population Council, Washington, DC
Muthén BO (2001) Latent variable mixture modeling. In: New developments and techniques in structural equation modeling. Psychology Press, pp 21-54

Muthén B (2004) Latent variable analysis. Sage Handb Quant Methodol Soc Sci 345:106-109

Napierala Mavedzenge S, Olson R, Doyle AM, Changalucha J, Ross DA (2011) The epidemiology of HIV among young people in sub-Saharan Africa: know your local epidemic and its implications for prevention. J Adolesc Health 49:559-567. https://doi. org/10.1016/j.jadohealth.2011.02.012

Population Council (2015) Resource manual: building assets toolkit: developing positive benchmarks for adolescent girls. Population Council, New York

Price JT, Rosenberg NE, Vansia D et al (2018) Predictors of HIV, HIV risk perception, and HIV worry among adolescent girls and young women in Lilongwe, Malawi. J Acquir Immune Defic Syndr 77(1):53-63. https://doi.org/10.1097/QAI. 0000000000001567

Pulerwitz J, Barker G (2008) Measuring attitudes toward gender norms among young men in Brazil: development and psychometric evaluation of the GEM scale. Men Masculinities 10:322-338. https://doi.org/10.1177/1097184X06298778

Rimal RN, Brown J, Mkandawire G, Folda L, Böse K, Creel AH (2009) Audience segmentation as a social-marketing tool in health promotion: use of the risk perception attitude framework in HIV prevention in Malawi. Am $\mathrm{J}$ Public Health 99(12):2224-2229. https://doi.org/10.2105/ajph.2008.155234

Santelli JS, Edelstein ZR, Mathur S et al (2013) Behavioral, biological, and demographic risk and protective factors for new HIV infections among youth, Rakai, Uganda. J Acquir Immune Defic Syndr 63(3):393-400. https://doi.org/10.1097/ QAI.0b013e3182926795

Santelli JS, Mathur S, Song X et al (2015) Rising school enrollment and declining HIV and pregnancy risk among adolescents in Rakai District, Uganda, 1994-2013. Glob Soc Welf. https://doi. org/10.1007/s40609-015-0029-x

Saul J, Bachman G, Allen S, Toiv NF, Cooney C (2018) The DREAMS core package of interventions: a comprehensive approach to preventing HIV among adolescent girls and young women. PLoS ONE 13(12):e0208167. https://doi.org/10.1371/ journal.pone.0208167

Schwarz G (1978) Estimating the dimension of a model. Ann Stat 6:461-464. https://doi.org/10.1214/aos/1176344136

Sgaier S, Engl E, Kretschmer S (2018) Time to scale psychobehavioral segmentation in global development. Stanf Soc Innov Rev 48-55

UNAIDS (2016a) AIDS by the numbers. In: UNAIDS: joint united nations programme on HIV/AIDS, Geneva

UNAIDS (2016b) Prevention gap report. In: Joint united national programme on HIV/AIDS (UNAIDS), Geneva

Underwood CR, Schwandt HM (2015) Assessing girls' HIV vulnerability: evidence from Botswana, Malawi and Mozambique. Health Policy Plan 31(6):729-735. https://doi.org/10.1093/hea $\mathrm{pol} / \mathrm{czv} 123$

Underwood C, O'Brien M, Skinner J (2009) Vulnerable girls and HIV in sub-Saharan Africa: a literature and program review. Johns Hopkins Bloomberg School of Public Health/Center for Communication Programs, Baltimore

Vu L, Pulerwitz J, Burnett-Zieman B, Banura C, Okal J, Yam E (2017) Inequitable gender norms from early adolescence to young adulthood in Uganda: tool validation and differences across age groups. J Adolesc Health 60:S15-S21. https://doi.org/ 10.1016/j.jadohealth.2016.09.027

Wachira FW, Mathai M, Kathuku DM (2019) Family connectedness and its association with sexual risk-taking among undergraduate 
students at the University of Nairobi. EA Health Res J 3:24-30. https://doi.org/10.24248/EAHRJ-D-18-00027

Wesson P, Lippman SA, Neilands TB et al (2019) Multilevel genderequitable norms and risk of HIV and herpes simplex virus type 2 acquisition among young South African women: a longitudinal analysis of the HIV Prevention Trials Network 068 Cohort.
J Adolesc Health 65(6):730-737. https://doi.org/10.1016/j.jado health.2019.07.010

Publisher's Note Springer Nature remains neutral with regard to jurisdictional claims in published maps and institutional affiliations.

\section{Affiliations}

\section{Sanyukta Mathur ${ }^{1} \cdot$ Nanlesta Pilgrim $^{2} \cdot$ Sangram Kishor Patel ${ }^{3} \cdot$ Jerry Okal $^{4} \cdot$ Victor Mwapasa $^{5}$. Effie Chipeta ${ }^{5} \cdot$ Maurice Musheke $^{6} \cdot$ Bidhubhusan Mahapatra $^{3} \cdot$ Julie Pulerwitz $^{1}$}

1 Population Council, 4301 Connecticut Ave, Suite 280, Washington, DC, USA

2 Independent Consultant, Washington, DC, USA

3 Population Council, New Delhi, India

4 Population Council, Nairobi, Kenya
5 Centre for Reproductive Health, College of Medicine, Blantyre, Malawi

6 Independent Consultant, Lusaka, Zambia 